\title{
Effectiveness of a 23-valent pneumococcal polysaccharide vaccine for the prevention of pneumococcal pneumonia in the elderly with chronic respiratory diseases: a case-control study of a single center
}

\author{
Toshihiro Masuda ${ }^{1}$, Eiji Nakatani ${ }^{2,3^{*}}$, Toshihiro Shirai ${ }^{1}$, Taisuke Akamatsu' ${ }^{1}, K^{\prime}$ anami Tamura', Shingo Takahashi ${ }^{1}$, \\ Yuko Tanaka' ${ }^{1}$, Hirofumi Watanabe ${ }^{1}$, Yoshinari Endo ${ }^{1}$, Takahito Suzuki ${ }^{1}$, Mika Saigusa', Akito Yamamoto ${ }^{1}$, \\ Satoru Morita ${ }^{1}$, Yoko Sato ${ }^{2}$ and Kazuhiro Asada ${ }^{1}$
}

\begin{abstract}
Background: The effectiveness of the 23-valent pneumococcal polysaccharide vaccine (PPSV23) in preventing pneumococcal pneumonia has been controversial.

Methods: To evaluate the effectiveness of the PPSV23 in elderly outpatients with chronic respiratory diseases, we carried out a case-control study, including 4128 outpatients aged $\geq 65$ years, in the respiratory department.

Results: There were 320 vaccinated patients, of which 164 were diagnosed with pneumococcal pneumonia. The adjusted odds ratio was 0.39 (95\% confidence interval (Cl), 0.17 to 0.89 ). In the subsets consisting of age groups $\geq 70$ and $\geq 75$ years, the adjusted odds ratio $(95 \% \mathrm{Cl})$ was respectively 0.16 (0.04 to 0.67$)$ and 0.15 (0.02 to 1.12).

Conclusion: This real-world study suggests that PPSV23 can be useful in preventing pneumococcal pneumonia in the elderly with chronic respiratory diseases.

Keywords: Chronic respiratory disease, Elderly, Pneumococcal polysaccharide vaccine, Pneumococcus, Pneumonia, Vaccine
\end{abstract}

\section{Background}

Streptococcus pneumoniae can cause pneumonia and invasive pneumococcal diseases (IPDs), which result in considerable morbidity and mortality worldwide [1, 2]. The Advisory Committee on Immunization Practices recommends the use of the 23-valent pneumococcal polysaccharide vaccine (PPSV23) or the 13-valent

\footnotetext{
*Correspondence: nakatani.eiji.int@gmail.com

${ }^{2}$ Division of Clinical Biostatistics, Research Support Center, Shizuoka

General Hospital, 4-27-1, Kita-ando, Aoi, Shizuoka 420-8527, Japan

Full list of author information is available at the end of the article
}

pneumococcal conjugate vaccine (PCV13) for all the elderly (age $\geq 65$ years) and for immunocompromised adults [3]. In Japan, the PPSV23 coverage of people aged $\geq 65$ years was $32.4 \%$ in 2019 [4], and that of the PCV13, which is not covered by Japanese universal health insurance, has not been reported because of the extremely small number of people vaccinated. The effectiveness of the PPSV23 in preventing IPD has been reported, its effectiveness in preventing pneumococcal pneumoniae has been inconsistent [5-7]. Some researchers have targeted both healthy individuals and patients with various diseases at nursing home residences $[6,8]$. 
We hypothesized that the PPSV23 would be useful in preventing pneumococcal pneumonia in elderly outpatients with chronic respiratory diseases. This study aimed to assess the effectiveness of the PPSV23 among elderly outpatients in clinical practice.

\section{Methods}

\section{Study design and population}

This study was a retrospective case-control design. The target population was defined as outpatients aged $\geq 65$ years, with chronic respiratory diseases, treated between 2015 and 2017 in the respiratory department of Shizuoka General Hospital. From this sample, the case and control groups consisted of patients with and without pneumococcal pneumonia, respectively. Patients who had been vaccinated with PCV13 were excluded.

\section{Diagnosis of pneumococcal pneumonia}

Respiratory physicians diagnosed pneumonia based on clinical findings such as fever, hypothermia, chills, cough, sputum production, pleuritic chest pain, fatigue, tachypnea, white blood cell count $>9300$, or $<4000$ cells/ $\mathrm{mm}^{3}$, and new pulmonary infiltrates on chest radiography [2]. In this study, all patients with pneumonia met these criteria. Pneumococcal pneumonia was diagnosed based on the positive results of urine pneumococcal antigen and sputum culture, but a negative blood culture for pneumococcus.

\section{Definitions}

The chronic respiratory diseases in this study included lung cancer, asthma, chronic obstructive pulmonary disease (COPD), interstitial pneumonia, pulmonary non-tuberculous mycobacteriosis (NTM), pulmonary tuberculosis, and others. The history of PPSV23 vaccination was obtained from medical records and declarations by patients or their families. Patients were considered vaccinated when they had received the PPSV23 within five years prior to the diagnosis of pneumonia. Patients without medical records or whose families had no knowledge of their vaccination statuses were considered unvaccinated.

\section{Statistical analysis}

The chi-squared tests for categorical variables and t-tests for continuous variables were used in comparing both groups. To evaluate the effectiveness of the PPSV23, we performed a logistic regression analysis, and then the odds ratio (OR), 95\% confidence interval (CI), and $p$ value (based on Wald test) were calculated. The adjusted OR was estimated by the quantile stratification method of propensity scores. The propensity score was estimated using multivariate logistic regression models with potential confounders as covariates, which included all variables of Table 1 . We also made two subsets: those $\geq 70$ years, and $\geq 75$ years, and compared their adjusted ORs with that in all patients. As a sensitivity analysis, we estimated double-robust adjusted OR in case-control studies under causal inference [9], and we confirmed whether the point estimation of OR, as mentioned above, was overestimating the effect.

To confirm the efficacy of the vaccine for each age group ( 65 to $<70$ years, 70 to $<75$ years, and $\geq 75$ years), crude ORs, ORs adjusted for risk factors, and their 95\% confidence intervals were calculated. Risk factors for pneumococcal pneumonia were identified as follows. Variables for which the $p$ value of the comparison test between the case and control groups was less than 0.05 were considered as candidate risk factors, and these variables were entered into a multivariate

\begin{tabular}{|c|c|c|c|}
\hline Variable and category (reference) & $\begin{array}{l}\text { Case group } \\
(n=164)\end{array}$ & $\begin{array}{l}\text { Control group } \\
(n=4,054)\end{array}$ & $p$ value \\
\hline Age, years ${ }^{\mathrm{a}}$ & $76.2 \pm 7.3$ & $75.1 \pm 6.7$ & 0.127 \\
\hline $65-69$ & $32(19.5)$ & $984(24.3)$ & 0.153 \\
\hline $70-74$ & $44(26.8)$ & $1,098(27.1)$ & \\
\hline $75-79$ & $36(22.0)$ & $950(23.4)$ & \\
\hline $80+$ & $56(34.1)$ & $1,063(26.2)$ & \\
\hline Male (vs. female) & $113(68.9)$ & $2,525(62.3)$ & 0.100 \\
\hline Smoking & & & 0.001 \\
\hline Non-smokers & $37(22.6)$ & $1,198(29.6)$ & \\
\hline Current smokers & $108(65.9)$ & $2,068(51.0)$ & \\
\hline Ex-smokers & $19(11.6)$ & $788(19.4)$ & \\
\hline \multicolumn{4}{|l|}{$\begin{array}{l}\text { Chronic respiratory diseases (vs. } \\
\text { absent) }\end{array}$} \\
\hline Asthma & $30(18.3)$ & $685(16.9)$ & 0.671 \\
\hline COPD & $42(25.6)$ & $959(23.6)$ & 0.574 \\
\hline Lung cancer & $45(27.4)$ & $1,594(39.3)$ & 0.002 \\
\hline Interstitial pneumonia & $29(17.7)$ & $703(17.3)$ & 0.916 \\
\hline NTM & $10(6.1)$ & $449(11.1)$ & 0.054 \\
\hline Others $^{b}$ & $48(29.3)$ & $746(18.4)$ & 0.001 \\
\hline Diabetes (vs. absent) & 65 (39.6) & $1,209(29.8)$ & 0.023 \\
\hline Chronic heart disease (vs. absent) & $95(57.9)$ & $1,891(46.6)$ & 0.005 \\
\hline $\begin{array}{l}\text { Chronic kidney disease (vs. } \\
\text { absent) }\end{array}$ & $13(7.9)$ & $299(7.4)$ & 0.761 \\
\hline $\begin{array}{l}\text { Systemic corticosteroid user (vs. } \\
\text { absent) }\end{array}$ & 65 (39.6) & $1,189(29.3)$ & 0.007 \\
\hline
\end{tabular}

Values are expressed as numbers and proportions in parentheses

${ }^{a}$ Mean \pm SD

b Other chronic respiratory diseases included chronic pulmonary aspergillosis, old pulmonary tuberculosis, sarcoidosis, and chronic cough

COPD, chronic obstructive pulmonary disease; NTM, non-tuberculous mycobacteriosis 
logistic regression model. In this multivariate model, variables with $p$ values less than 0.05 were identified as risk factors. Furthermore, to extract variables containing different categories of pneumococcal pneumonia proportions in different age groups, an interaction term test using a logistic regression model was performed.

A $p$ value of $<0.05$ was considered to be statistically significant. Statistical analyses were performed using SAS version 9.4 (SAS Institute, Cary, NC, USA).

\section{Results}

\section{Patients background}

Between January 1, 2015, and December 31, 2017, 4274 outpatients aged $\geq 65$ years with chronic respiratory diseases visited our department. Of 4274, 45 had been vaccinated with PCV13 and 11 with PPSV23 and PCV13. These were excluded from the study, which included 4218 patients. The patient flow is shown in Fig. 1. A total of 320 patients received the PPSV23, while 3898 did not. Of the 320 vaccinated patients, 6 developed pneumococcal pneumonia, compared to 158 of the 3898 unvaccinated patients.

The baseline characteristics of the case and control group on January 1, 2015, are shown in Table 1. Patients in the case group were more current-smokers, as well as had other chronic respiratory diseases, diabetes, chronic heart disease, and had higher use of systemic corticosteroids, than the control group. The number of patients in the case group with lung cancer was less than that of the control group.

\section{Effectiveness of the vaccine against pneumococcal pneumonia}

Pneumococcal pneumonia prevention crude OR $(95 \%$ CI) was $0.45(0.20-1.03, p=0.059)$, and the adjusted OR was 0.39 (0.17-0.89) (Fig. 2). There was a trend toward lower adjusted ORs in the subset restricted to only the more elderly: OR (95\% CI): $0.39(0.17-0.89)$ for those aged $\geq 65$ years, $0.16(0.04-0.67)$ for subset 1 ( $\geq 70$ years), and $0.15(0.02-1.12)$ for subset 2 ( $\geq 75$ years). In the sensitivity analysis, the double-robust adjusted ORs in patients of $\geq 65, \geq 70$, and $\geq 75$ years old were respectively $0.35,0.14$ and 0.13 , thus, the above adjusted ORs were conservative and not overestimating.

\section{Age-specific effectiveness and patients' characteristics}

Age-specific patients' characteristics were presented in Table 2 . The crude ORs ( $95 \% \mathrm{CI})$ by age for vaccine efficacy against pneumococcal pneumonia in those aged 65 to $<70$ years, 70 to $<75$ years, and $\geq 75$ years were 1.44 (0.49-4.22), $0.24(0.03-1.74)$, and $0.17(0.02-1.24)$, respectively (Table 2 ). The results of feeding the variables that were significant in Table 1 into a multivariate logistic regression model are shown in Additional file 1: Table 1. In this multivariate model, smoking, lung cancer, other chronic respiratory diseases, and systemic corticosteroid user were considered as risk factors. The ORs $(95 \% \mathrm{CI})$ adjusted for these risk factors for each age group were 1.34 (0.45-4.02), $0.22(0.03-1.59)$, and $0.17(0.02-1.20)$ (Table 2).

The variables containing categories with different rates of pneumococcal pneumonia according to age according to the interaction term test were lung cancer $(p=0.013)$,

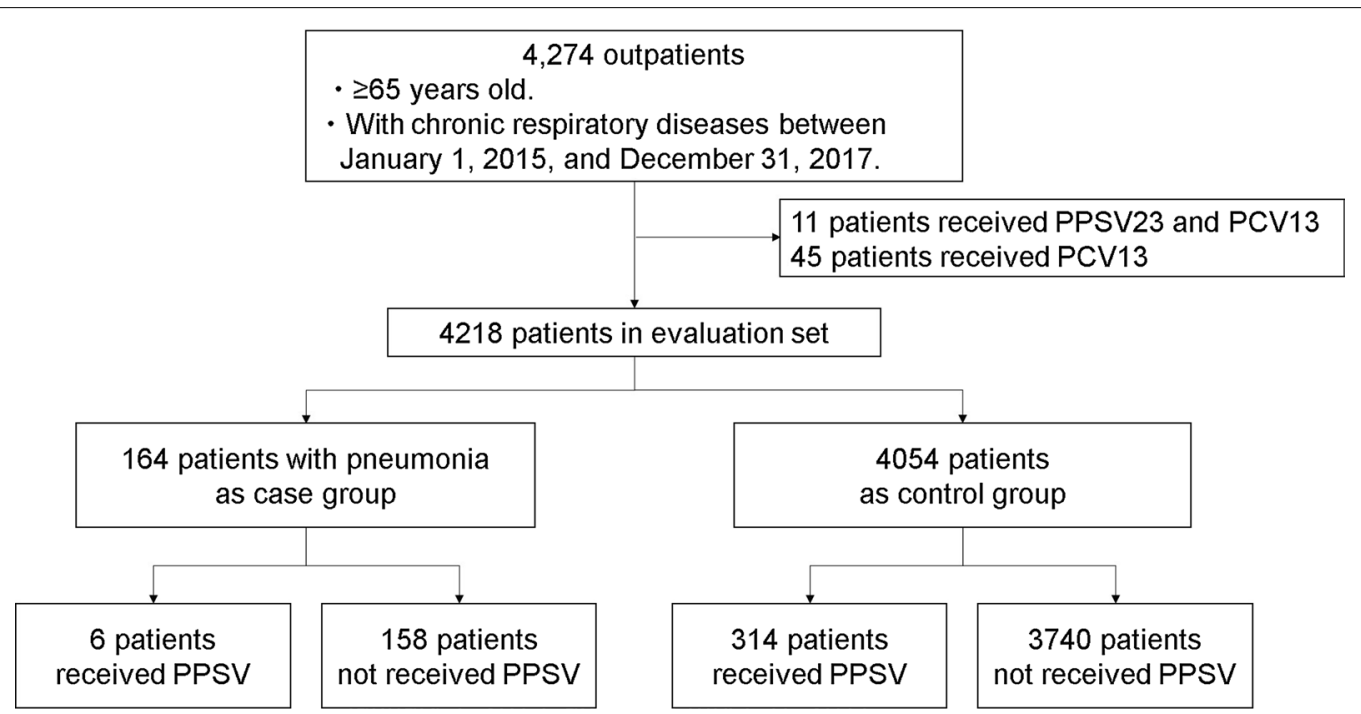

Fig. 1 Patient flow. PPSV23: 23-valent pneumococcal polysaccharide vaccine, PCV13: 13-valent pneumococcal conjugate vaccine 


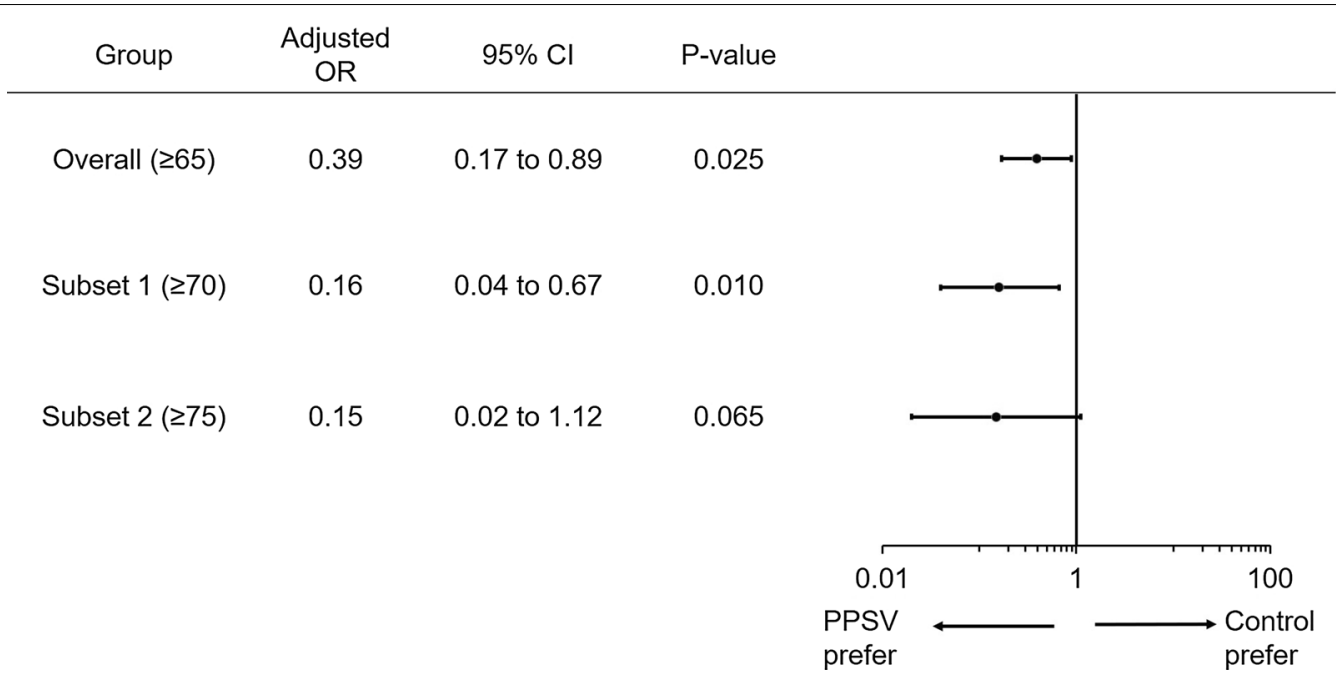

Fig. 2 Effectiveness of vaccines in pneumococcal pneumonia in age-related subsets. OR, odds ratio; Cl, confidence interval; PPSV23, 23-valent pneumococcal polysaccharide vaccine. The lower adjusted ORs in subsets of older patients were estimated, suggesting that the PPSV23 can be more effective for older patients. The adjusted OR was adjusted using the quantile category of propensity scores

Table 2 Age-specific effectiveness and patients' characteristics

\begin{tabular}{|c|c|c|c|c|c|c|c|}
\hline \multirow[t]{2}{*}{ Variable and category (reference) } & \multicolumn{2}{|l|}{65 to $<70$ years } & \multicolumn{2}{|l|}{70 to $<75$ years } & \multicolumn{2}{|l|}{$\geq 75$ years } & \multirow{2}{*}{$\begin{array}{l}p \text { value of interaction } \\
\text { term with age } \\
\text { category }\end{array}$} \\
\hline & $\begin{array}{l}\text { Case } \\
(n=30)\end{array}$ & $\begin{array}{l}\text { Control } \\
(n=974)\end{array}$ & $\begin{array}{l}\text { Case } \\
(\mathrm{n}=44)\end{array}$ & $\begin{array}{l}\text { Control } \\
(n=1,085)\end{array}$ & $\begin{array}{l}\text { Case } \\
(\mathrm{n}=90)\end{array}$ & $\begin{array}{l}\text { Control } \\
(\mathrm{n}=1,995)\end{array}$ & \\
\hline PPSV23 (vs. absent) & $4(13.3)$ & $94(9.7)$ & $1(2.3)$ & $97(8.9)$ & $1(1.1)$ & $123(6.2)$ & 0.090 \\
\hline Crude odds ratio (95\% Cl) & $1.44(0.49-4.22)$ & & $0.24(0.03-1.74)$ & & $0.17(0.02-1.24)$ & & \\
\hline Adjusted odds ratio ${ }^{\mathrm{a}}(95 \% \mathrm{Cl})$ & $1.34(0.45-4.02)$ & & $0.22(0.03-1.59)$ & & $0.17(0.02-1.20)$ & & 0.102 \\
\hline Male (vs. female) & 19 (63.3) & $585(60.1)$ & $33(75.0)$ & $696(64.2)$ & $61(67.8)$ & $1244(62.4)$ & 0.736 \\
\hline Smoking (vs. non-smokers) & & & & & & & 0.727 \\
\hline Current smokers & $21(70.0)$ & $522(53.6)$ & $33(75.0)$ & $578(53.3)$ & $54(60.0)$ & $968(48.5)$ & \\
\hline Ex-smokers & $5(16.7)$ & $215(22.1)$ & $4(9.1)$ & $222(20.5)$ & $10(11.1)$ & $351(17.6)$ & \\
\hline \multicolumn{8}{|l|}{ Chronic respiratory diseases } \\
\hline Asthma (vs. absent) & $5(16.7)$ & $180(18.5)$ & $11(25.0)$ & $189(17.4)$ & $14(15.6)$ & $316(15.8)$ & 0.506 \\
\hline COPD (vs. absent) & $6(20.0)$ & $210(21.6)$ & $16(36.4)$ & $282(26.0)$ & $20(22.2)$ & $467(23.4)$ & 0.360 \\
\hline Lung cancer (vs. absent) & $9(30.0)$ & $415(42.6)$ & $19(43.2)$ & $409(37.7)$ & $17(18.9)$ & $770(38.6)$ & 0.013 \\
\hline Interstitial pneumonia (vs. absent) & $7(23.3)$ & $167(17.2)$ & $8(18.2)$ & $195(18.0)$ & $14(15.6)$ & $340(17.0)$ & 0.646 \\
\hline NTM (vs. absent) & $11(36.7)$ & $167(17.2)$ & $10(22.7)$ & $191(17.6)$ & $27(30.0)$ & $388(19.5)$ & 0.405 \\
\hline $\begin{array}{l}\text { Others chronic respiratory } \\
\text { diseases } \\
\text { (vs. absent) }\end{array}$ & $5(16.7)$ & $87(8.9)$ & $4(9.1)$ & $118(10.9)$ & $28(31.1)$ & $332(16.6)$ & 0.218 \\
\hline Diabetes (vs. absent) & $9(30.0)$ & $253(26.0)$ & $26(59.1)$ & $350(32.3)$ & $30(33.3)$ & $606(30.4)$ & 0.036 \\
\hline Chronic heart disease (vs. absent) & $12(40.0)$ & $350(35.9)$ & $25(56.8)$ & $504(46.5)$ & $58(64.4)$ & $1036(51.9)$ & 0.736 \\
\hline Chronic kidney disease (vs. absent) & 0 & $28(2.9)$ & $3(6.8)$ & $25(2.3)$ & 0 & $64(3.2)$ & 0.998 \\
\hline $\begin{array}{l}\text { Systemic corticosteroid user (vs. } \\
\text { absent) }\end{array}$ & $15(50.0)$ & $311(31.9)$ & $26(59.1)$ & $363(33.5)$ & $24(26.7)$ & $515(25.8)$ & 0.029 \\
\hline
\end{tabular}

Bold value indicates statistical significance

a The odds ratios for PPSV23 were calculated for adjusting smoking, lung cancer, other chronic respiratory diseases, and systemic corticosteroid user

b Other chronic respiratory diseases included chronic pulmonary aspergillosis, old pulmonary tuberculosis, sarcoidosis, and chronic cough

$\mathrm{Cl}$, confidence interval; COPD, chronic obstructive pulmonary disease; NE, not evaluated; NTM, non-tuberculous mycobacteriosis; PPSV23, 23-valent pneumococcal polysaccharide vaccine 
diabetes mellitus $(p=0.036)$, and presence of systemic corticosteroid use $(p=0.029)$ (Table 2$)$.

\section{Discussion}

This study found that the PPSV23 prevented pneumococcal pneumonia in older patients (age $\geq 65$ years) with chronic respiratory diseases, and could be more effective for the elderly (patients aged $\geq 70$ years). To the best of our knowledge, this is the first real-world study that assesses the effectiveness of the PPSV23 in older patients with chronic respiratory disease in a single center.

In previous studies, the effectiveness of the vaccine against pneumococcal pneumonia was controversial. In the results of a meta-analysis of 18 randomized trials [5], the PPSV23 reduced the risk of IPDs such as bacteremia, meningitis, and bacteremic pneumonia (OR [95\% $\mathrm{CI}]: 0.26[0.15-0.46])$ and pneumococcal pneumonia (0.46 [0.25-0.84]). However, some studies reported that the PPSV23 did not reduce pneumococcal pneumonia $[6,7,10]$. The EVAN-65 study in community-dwelling patients [11] showed that the hazard ratios (HR) for the risk of pneumococcal pneumonia in vaccinated patients compared with non-vaccinated patients were not different (HR [95\% CI]: 0.61 [0.35-1.06]). Similarly, another study in elderly patients with chronic respiratory diseases showed no difference $(0.76$ [0.30-1.90]) [12]. These conflicting results can be due to the difficulties of accurately diagnosing pneumococcal pneumonia and the use of non-validated diagnostic tests [13]. In this study, we included non-invasive cases according to specific diagnostic criteria of pneumonia, urine pneumococcal antigen, and sputum culture, and we are convinced that these results are close to correct.

One previous case-control study suggested that $85-90 \%$ of adults aged 55 and younger achieved the prevention of invasive pneumococcal infections, but this effect was reduced with increasing age, and no protection was shown in the population aged $\geq 80$ years [14]. Another study suggested that the prevention of community-onset pneumococcal pneumonia was effective in people aged $65-75$ years but not effective in those aged $\geq 75$ years in Japan [15]. The population-based retrospective cohort study in Germany reported that the prevention of pneumococcal pneumonia was not effective at all in people aged $\geq 80$ years [16]. These studies suggest that poorer effectiveness might be due to immunosenescence, which refers to the decline of the immune system associated with aging [17]. However, this study found that the OR was much decreased in older people, which could imply that older people can acquire antibodies with the PPSV23 vaccination, and we proposed that older people be re-vaccinated because of an anticipated decline in the effectiveness of the vaccine over time.
Almost all patients with chronic respiratory diseases in this study had risk factors for pneumonia [18]. Previously, most studies on the PPSV23 targeted nursing home residences or healthy adults, and controversial results have been reported on non-invasive pneumonia [8]. Our findings suggest the importance of vaccinating chronic respiratory patients in clinical practice.

There were several limitations. First, this study was a retrospective single-center study, and a complete confounding adjustment was not done. Second, we did not assess the severity of the underlying diseases. The study population was biased, consisting mainly of moderate to severe disease cases. Third, we did not regularly identify the serotype of each pneumococcal pneumonia. Fourth, the vaccination status of unvaccinated persons was defined based on the lack of medical records of vaccination, and some vaccinated patients may have been misclassified as unvaccinated. Fifth, in this study, we were not able to investigate the patients' history of seasonal influenza vaccination. This may affect the risk of pneumococcal infections.

In summary, the PPSV23 can be useful in preventing pneumococcal pneumonia among the elderly with chronic respiratory diseases.

\section{Supplementary Information}

The online version contains supplementary material available at https://doi. org/10.1186/s12890-021-01491-w.

Additional file 1: Table 1. The result of multivariable logistic regression analysis to identify risk factors for pneumococcal pneumonia.

Acknowledgements

Not applicable.

Authors' contributions

Study concept and design: TM, EN, TS; acquisition of data: TM, TS, TA, KT, ST, YT, HW, YE, TS, MS, AY, SM, KA; data analysis: TM, EN, YS; interpretation of data:TM, EN, YS, TS; first draft of the manuscript: TM. All authors read and approved the final manuscript.

\section{Funding}

There was no funding support.

\section{Availability of data and materials}

The datasets used and/or analysed during the current study are available from the corresponding author on reasonable request.

\section{Declarations}

Ethics approval and consent to participate

This study conforms to the Ethical Principles for Medical Research Involving Human Subjects issued by the Ministry of Health, Labour and Welfare and the Ministry of Education, Culture, Sports, Science, and Technology in Japan. Following these guidelines, the Shizuoka General Hospital Research Ethical Committee determined that individual patient informed consent was not required because this study was an analysis study of existing information and patients were given the right to refuse participation by disclosure. After obtaining the approval of this committee (SGHIRB\#2017062) and publishing the disclosure 
document on Shizuoka General Hospital's website, the information of each individual was anonymized, and the analysis was conducted.

\section{Consent for publication}

Not applicable.

\section{Competing interests}

The authors have no conflicts of interest to disclose.

\section{Author details}

1 Department of Respiratory Medicine, Shizuoka General Hospital, 4-27-1, Shizuoka, Japan. ${ }^{2}$ Division of Clinical Biostatistics, Research Support Center, Shizuoka General Hospital, 4-27-1, Kita-ando, Aoi, Shizuoka 420-8527, Japan.

${ }^{3}$ Graduate School of Public Health, Shizuoka Graduate University of Public Health, 4-27-2 Kitaando, Aoi-ku, Shizuoka 420-0881, Japan.

\section{Received: 1 March 2021 Accepted: 8 April 2021}

Published online: 16 April 2021

\section{References}

1. Said MA, Johnson HL, Nonyane BAS, Deloria-Knoll M, O'brien $\mathrm{KL}$, for the AAPBST. Estimating the burden of pneumococcal pneumonia among adults: a systematic review and meta-analysis of diagnostic techniques. PLOS ONE. 2013;8:e60273.

2. Mandell LA, Wunderink RG, Anzueto A, Bartlett JG, Campbell GD, Dean $\mathrm{NC}$, et al. Infectious Diseases Society of America/American Thoracic Society consensus guidelines on the management of community-acquired pneumonia in adults. Clin Infect Dis. 2007;44(Suppl 2):S27-72.

3. Tomczyk S, Bennett NM, Stoecker C, Gierke R, Moore MR, Whitney CG, et al. Use of 13-valent pneumococcal conjugate vaccine and 23-valent pneumococcal polysaccharide vaccine among adults aged $\geq 65$ years: recommendations of the Advisory Committee on Immunization Practices (ACIP). MMWR Morb Mortal Wkly Rep. 2014;63:822-5.

4. Number of people immunized against Streptococcus pneumoniae in the elderly. Ministry of Health, Labour and Welfare. https://www.mhlw.go.jp/ topics/bcg/other/5.html. Accessed 25 Mar 2021.

5. Moberley S, Holden J, Tatham DP, Andrews RM. Vaccines for preventing pneumococcal infection in adults. Cochrane Database Syst Rev. 2013;23:CD000422.

6. Jackson LA, Neuzil KM, Yu O, Benson P, Barlow WE, Adams AL, et al. Effectiveness of pneumococcal polysaccharide vaccine in older adults. N Engl J Med. 2003;348:1747-55.

7. Musher DM, Rueda-Jaimes AM, Graviss EA, Rodriguez-Barradas MC. Effect of pneumococcal vaccination: a comparison of vaccination rates in patients with bacteremic and nonbacteremic pneumococcal pneumonia. Clin Infect Dis. 2006;43:1004-8.

8. Maruyama T, Taguchi O, Niederman MS, Morser J, Kobayashi H, Kobayashi T, et al. Efficacy of 23-valent pneumococcal vaccine in preventing pneumonia and improving survival in nursing home residents: double blind, randomised and placebo controlled trial. BMJ. 2010;340:C1004.

9. Tchetgen Tchetgen EJ, Rotnitzky A. Double-robust estimation of an exposure-outcome odds ratio adjusting for confounding in cohort and case-control studies. Stat Med. 2011;30:335-47.

10. Huss A, Scott P, Stuck AE, Trotter C, Egger M. Efficacy of pneumococcal vaccination in adults: a meta-analysis. CMAJ. 2009;180:48-58.

11. Vila-Córcoles A, Ochoa-Gondar O, Hospital I, Ansa X, Vilanova A, Rodríguez T, et al. Protective effects of the 23 -valent pneumococcal polysaccharide vaccine in the elderly population: the EVAN-65 study. Clin Infect Dis. 2006;43:860-8.

12. Ochoa-Gondar O, Vila-Corcoles A, Ansa X, Rodriguez-Blanco T, Salsench $E$, de Diego C, et al. Effectiveness of pneumococcal vaccination in older adults with chronic respiratory diseases: results of the EVAN-65 study. Vaccine. 2008;26:1955-62.

13. Musher DM. How effective is vaccination in preventing pneumococcal disease? Infect Dis Clin North Am. 2013;27:229-41.

14. Shapiro ED, Berg AT, Austrian R, Schroeder D, Parcells V, Margolis A, et al. The protective efficacy of polyvalent pneumococcal polysaccharide vaccine. N Engl J Med. 1991;325:1453-60.

15. Suzuki M, Dhoubhadel BG, Ishifuji T, Yasunami M, Yaegashi M, Asoh N, et al. Serotype-specific effectiveness of 23-valent pneumococcal polysaccharide vaccine against pneumococcal pneumonia in adults aged 65 years or older: a multicentre, prospective, test-negative design study. Lancet Infect Dis. 2017;17:313-21.

16. Kolditz M, Schmitt J, Pletz MW, Tesch F. Impact of pneumococcal polysaccharide vaccine on incidence and mortality after pneumonia in adults aged $>/=60$ years-a population-based retrospective cohort study. Clin Microbiol Infect. 2018;24:500-4.

17. Pera A, Campos C, Lopez N, Hassouneh F, Alonso C, Tarazona R, et al. Immunosenescence: implications for response to infection and vaccination in older people. Maturitas. 2015;82:50-5.

18. Ishiguro T, Takayanagi N, Yamaguchi S, Yamakawa H, Nakamoto K, Takaku $Y$, et al. Etiology and factors contributing to the severity and mortality of community-acquired pneumonia. Intern Med. 2013;52:317-24.

\section{Publisher's Note}

Springer Nature remains neutral with regard to jurisdictional claims in published maps and institutional affiliations.
Ready to submit your research? Choose BMC and benefit from:

- fast, convenient online submission

- thorough peer review by experienced researchers in your field

- rapid publication on acceptance

- support for research data, including large and complex data types

- gold Open Access which fosters wider collaboration and increased citations

- maximum visibility for your research: over 100M website views per year

At BMC, research is always in progress.

Learn more biomedcentral.com/submissions 